\title{
"Nova velha história": o mito da cobra grande em Cassiano Ricardo, Raul Bopp e Daniel Munduruku
}

\author{
Telma Borges da Silva ${ }^{1}$
}

\begin{abstract}
Resumo: Este trabalho teve por objetivo realizar uma análise comparativa entre os livros Martim Cererê, de Cassiano Ricardo, Cobra Norato, de Raul Bopp e O sumiço da noite, de Daniel Munduruku. A abordagem teórico-metodológica baseou-se na noção de perspectivismo, de Eduardo Viveiros de Castro, na ideia de enunciado, de Michel Foucault e em algumas considerações simbólicas sobre a serpente, a partir da qual destacou-se o modo como o mito da cobra grande é apropriado por cada um desses autores e os diferentes efeitos de sentido que produzem. Enquanto nos textos dos escritores modernistas, a cobra não cria um ponto de vista próprio, pois age em favor do colonizador, no texto de Munduruku ela produz uma perspectiva própria, age no mundo para garantir sua sobrevivência, de modo que é possível afirmar a existência de uma percepção mútua de como o mundo se exprime das cobras.
\end{abstract}

Palavras-chave: Perspectivismo. Literatura modernista. Literatura contemporânea. Enunciado. Mito da Cobra Grande.

\section{"New old story": the myth of the big Snake in Cassiano Ricardo, Raul Bopp and Daniel Munduruku}

\begin{abstract}
This work aimed to carry out a comparative analysis between the books Martim Cererê, by Cassiano Ricardo, Cobra Norato, by Raul Bopp, and O sumiço da noite by Daniel Munduruku. The theoretical-methodological approach was based on the notion of perspectivism, by Eduardo Viveiros de Castro, on the idea of enunciated, by Michel Foucault and on some symbolic considerations about the snake, from which the myth of the snake was highlighted great is appropriate for each of these authors and the different effects of meaning they produce. While in the texts of modernist writers, the snake does not create its own point of view, as it acts in favor of the colonizer, in Munduruku's text it is one that produces its own perspective, it acts in the world to ensure its survival, so that it is possible affirm the existence of a mutual perception of how the world expresses itself in snakes' point of view.
\end{abstract}

Keywords: Perspectivism. Modernist Literature. Contemporary Literature. Utterance. Myth of Big Snake.

\section{"Nueva vieja historia": el mito de la gran serpiente en Cassiano Ricardo, Raul Bopp y Daniel Munduruku}

\footnotetext{
${ }^{1}$ Doutor em Literatura Comparada. Professora da Faculdade de Educação da Universidade Federal de Minas Gerais. MG, Brasil. e-mail: teopretinha@gmail.com . Orcid: https://orcid.org/0000-0002-90195053.
} 
Resumen: Este trabajo tuvo como objetivo realizar un análisis comparativo entre los libros Martim Cererê, de Cassiano Ricardo, Cobra Norato, de Raul Bopp y O sumiço da noite, de Daniel Munduruku. El enfoque teórico-metodológico se basó en la noción de perspectivismo, de Eduardo Viveiros de Castro, en la idea de enunciado, de Michel Foucault y en algunas consideraciones simbólicas sobre la serpiente, de las cuales la forma en que el mito de la serpiente se destacó lo bueno que es apropiado para cada uno de estos autores y los diferentes efectos de significado que producen. Mientras que en los textos de los escritores modernistas la serpiente no crea su propio punto de vista, pues actúa a favor del colonizador, en el texto de Munduruku es aquella que produce su propia perspectiva, actúa en el mundo para asegurar su supervivencia, para que sea posible afirmar la existencia de una percepción mutua de cómo el mundo se expresa en serpientes.

Palabras clave: Perspectivismo. Literatura modernista. Literatura contemporánea. Enunciado. Mito de la gran Serpiente.

\section{Considerações iniciais}

Gostaria de iniciar esta reflexão fazendo provocações que vão me levar ao cerne da discussão proposta. Se eu dissesse que uma serpente, uma árvore, um indígena e um escritor são humanos, muitos questionamentos adviriam daí. O mais comum talvez fosse separar esse conjunto em dois grupos, colocando o escritor e o indígena de um lado e a serpente e a árvore do outro, sob o argumento de que o indígena e o escritor possuem uma alma que os humaniza, enquanto a serpente e a árvore não são portadoras tal atributo. Esse talvez fosse um dos senões a essa proposição se levasse em conta a modelagem do pensamento ocidental sobre o mundo e os seres que o habitam. Entre o escritor e o indígena, com certeza haveria alguns graus de afastamento que colocariam o escritor no topo de uma cadeia hierárquica e o indígena na base desse sistema. Entre a árvore e a serpente, seguramente se atribuiria a esse animal um grau de inferioridade em relação à árvore, já que essa pode ser frutífera, tendo portanto utilidade para o homem, enquanto o réptil, à primeira vista, representa perigo para outros seres vivos. Se aproximo o indígena da serpente, ambos na base dessa escala hierárquica que forjei, que afinidades e disparidades podem ser daí depreendidas? São selvagens, vivem ou viviam distantes da civilização são duas possibilidades para aproximá-los. A diferença, posso supor, está no fato de que o indígena tem consciência da sua condição, ao passo que a serpente não.

Existem grupos humanos, como os "achuar da Amazônia, (...) que estabelecem uma diferença ontológica de grau, mas não de natureza entre plantas, homens e animais"? Para eles, plantas e animais são dotados de uma alma (wakan) similar à dos 
humanos, além de contarem com a intencionalidade e a reflexividade. Esse ponto de vista refuta o exercício reflexivo com o qual iniciei este texto, pois a serpente, a árvore, o indígena e o escritor são classificados como humanos dotados de sentimentos e com capacidade de comunicarem-se através de mensagem seu estado de espírito e comportamento.

Esse modo de ver o outro, não-humano, como humano, Eduardo Viveiros de Castro chamou de Perspectivismo, termo emprestado da filosofia para classificar as cosmologias ameríndias:

Trata-se da noção de que, em primeiro lugar, o mundo é povoado de muitas espécies de seres (além dos humanos propriamente ditos) dotados de consciência e de cultura e, em segundo lugar, de que cada uma dessas espécies vê a si mesma e às demais de modo bastante singular: cada uma se vê a si mesma como humana, vendo todas as demais como não humanas, isto é, como espécies de animais ou de espíritos. (CASTRO, 2004, p. 225).

Pretendo, neste trabalho, me valer do Perspectivismo para ler comparativamente Martim Cererê (1928), de Cassiano Ricardo; Cobra Norato (1931), de Raul Bopp e $O$ sumiço da noite (2006), de Daniel Munduruku, destacando o modo como o mito da cobra grande é apropriado por cada um desses autores. Antes, é preciso compreender, ainda que em largas pinceladas, o Perspectivismo.

\section{Perspectivismo como categoria de análise e mais}

No artigo "Perspectivismo e multinaturalismo na América indígena" (2004), o antropólogo Eduardo Viveiros de Castro questiona a oposição entre “'Natureza' e 'Cultura' realizando uma redistribuição de atributos paradigmáticos e binarizantes, como universal e particular, objetivo e subjetivo, físico e moral, fato e valor, dado e construído, necessidade e espontaneidade, imanência e transcendência, corpo e espírito, animalidade e humanidade, e outros tantos. Nesse primeiro exercício de reembaralhamento de cartas conceituais, o autor sugere o termo "multinaturalismo" para contrastar um aspecto do pensamento ameríndio em relação ao que ele denomina “cosmologias 'multiculturalistas' modernas". Enquanto no multiculturalismo há uma implicação mútua entre "unicidade da natureza e multiplicidade das culturas", que se garante pela particularidade subjetiva dos espíritos e do significado, no multinaturalismo ocorre a mútua universalidade objetiva dos corpos e da substância. 
Contrária a essas concepções, os ameríndios suporiam uma "unidade do espírito e uma diversidade dos corpos." Ou seja, "a cultura ou o sujeito seriam aqui a forma do universal, a natureza ou o objeto a forma do particular." (CASTRO, 2004, p. 226). Pela lógica ocidental, os domínios objetivo e subjetivo estão ontologicamente separados, sendo o primeiro o mundo exterior e o segundo o mundo interior.

O que motiva Viveiros de Castro e também este trabalho é uma concepção indígena segundo a qual os humanos, os animais, os vegetais e outras subjetividades existentes no universo são profundamente diferentes do modo "como esses seres vêem os humanos e se vêem a si mesmos." (CASTRO, 2004, p. 227). Nós, humanos, nos vemos como tais e os demais seres do universo como animais, vegetais ou espíritos. $\mathrm{Na}$ passagem abaixo, Castro avança sua reflexão para a compreensão necessária ao propósito deste trabalho:

Tipicamente, os humanos, em condições normais, vêem os humanos como humanos e os animais como animais; quanto aos espíritos, ver estes seres usualmente invisíveis é um signo seguro de que as 'condições' não são normais. Os animais predadores e os espíritos, entretanto, vêem os humanos como animais de presa, ao passo que os animais de presa vêem os humanos como espíritos ou como animais predadores: "O ser humano se vê a si mesmo como tal. A lua, a serpente, o jaguar e a mãe da varíola o vêem, contudo, como um tapir ou um pecari, que eles matam", anota Baer (1994:224) sobre os Matsiguenga. Vendo-nos como não-humanos, é a si mesmos que os animais e espíritos vêem como humanos. Eles se apreendem como, ou se tornam, antropomorfos quando estão em suas próprias casas ou aldeias, e experimentam seus próprios hábitos e características sob a espécie da cultura: vêem seu alimento como alimento humano (os jaguares vêem o sangue como cauim, os mortos vêem os grilos como peixes, os urubus vêem os vermes da carne podre como peixe assado etc.), seus atributos corporais (pelagem, plumas, garras, bicos etc.) como adornos ou instrumentos culturais, seu sistema social como organizado identicamente às instituições humanas (com chefes, xamãs, ritos, regras de casamento etc.). (CASTRO, 2004, p. 227).

Esse "ver como", para Castro, refere-se a perceptos, a uma dimensão sensorial, segundo a qual os animais e outros seres se veem como pessoas e sua forma manifesta pode ser entendida como uma 'roupa', a qual esconde uma forma interna humana visível apenas aos seres da mesma espécie. O perspectivismo, adverte Castro, "raramente se aplica em extensão a todos os animais (...)"; sua incidência mais frequente é entre os "grandes predadores e carniceiros, tais como o jaguar, a sucuri, os 
urubus ou a harpia, bem como sobre as presas típicas dos humanos, tais como o pecari, os macacos, os peixes, os veados ou o tapir." (CASTRO, 2004, p. 228).

Para o estudioso, é no universo mítico que o perspectivismo ameríndio encontra um lugar de conforto, onde “(...) a diferença dos pontos de vista é ao mesmo tempo anulada e exacerbada. (...) cada espécie de ser aparece aos outros seres como aparece para si mesma - como humana -, e entretanto age como se já manifestando sua natureza distintiva e definitiva de animal, planta ou espírito" (CASTRO, 2004, p. 229), o que leva o antropólogo a dizer que a humanidade e a não animalidade é a nossa condição original, já que a divisão mítica mostra "a natureza se afastando da cultura: os mitos contam como os animais perderam os atributos herdados ou mantidos pelos humanos. Enquanto os humanos são aqueles que continuaram iguais a si mesmos, os animais e os vegetais são o humano que perdeu algum atributo, a despeito de continuarem a ser humanos de modo não evidente. [P]ara os ameríndios, 'o referencial comum a todos os seres da natureza não é o homem enquanto espécie, mas a humanidade enquanto condição"” (DESCOLA ${ }^{2}$, apud CASTRO, 1986, p. 120). Há aqui o posicionamento de que as roupas animais escondem uma "essência" humano-espiritual comum entre humanos e não-humanos e se conecta com a concepção geral do perspectivismo. (CASTRO, 2004, p. 230). Sob esse ponto de vista, conhecer o outro é

[...] explicitar a parte do sujeito presente no objeto, de modo a reduzila a um mínimo ideal. Os sujeitos, tanto quanto os objetos, são vistos como resultantes de processos de objetivação: o sujeito se constitui ou reconhece a si mesmo nos objetos que produz, e se conhece objetivamente quando consegue se ver 'de fora', como um 'isso'. (CASTRO, 2004, p. 231).

Com base nessa perspectiva, pode-se dizer que os ameríndios da Amazônia, conforme tratados por Castro, são cosmocêntricos ao demonstrarem "o quão pouco humanos somos nós, que opomos humanos e não-humanos de um modo que eles nunca fizeram: para eles, natureza e cultura são parte de um mesmo campo sociocósmico." (CASTRO, 2004, p. 234). Ou seja, no perspectivismo ameríndio os predicados da humanidade ultrapassam os limites da espécie, "em uma demonstração de sabedoria 'ecosófica' (Århem, 1993) que devemos emular, tanto quanto permitam os limites de nosso objetivismo." (CASTRO, 2004, p. 235).

\footnotetext{
${ }^{2}$ DESCOLA, P. La nature domestique: symbolisme et praxis dans l'écologie des Achuar. Paris: Maison des Sciences de L'Homme, 1986.
} 
O animismo, que confere alma, humanidade a seres até então não-humanos, é um reconhecimento da "mestiçagem universal entre sujeitos e objetos, humanos e nãohumanos, a que nós modernos sempre estivemos cegos, por conta de nosso hábito tolo, para não dizer perverso, de pensar por dicotomias" (CASTRO, 2004, p. 235). Avançando na discussão, o antropólogo entra na categoria dos etnônimos, que "são nomes de terceiros, pertencem à categoria do 'eles', não à categoria do 'nós'”. Nomear é distinguir um sujeito dentre muitos, ao passo que as designações coletivas como "gente" significam "pessoas", "não membros da espécie humana". Expressam o ponto de vista do sujeito que fala. "Dizer então que os animais e espíritos são gente é dizer que são pessoas; é atribuir aos não-humanos as capacidades de intencionalidade consciente e de 'agência' que facultam a ocupação da posição enunciativa de sujeito." (CASTRO, 2004, p. 236). Aqui entra em cena a noção de ponto de vista, passível de existir nos seres dotados de alma.

Conforme Deleuze ${ }^{3}$ (apud CASTRO, 2004, p. 236), “[s]erá sujeito aquele que aceder ao ponto de vista." Ou seja, todo ser que ocupa a posição de sujeito se reconhece como da espécie humana, fazendo da humanidade uma consequência da subjetividade. A cultura, portanto, é a forma pela qual o sujeito experimenta sua natureza humana. Parafraseando Castro, posso dizer que as serpentes, como as árvores, numa equivalência de relações, veem a si mesmas como humanas, tal como os homens veem os humanos como humanos. Isso leva a uma importante conclusão: a condição comum aos humanos e animais é a humanidade, não a animalidade, porque 'humanidade' é o nome da forma geral do Sujeito. (CASTRO, 2004, p. 237). Mas as serpentes não parecem humanas aos humanos, nem os humanos às serpentes. Para Castro,

[o] que as cosmologias indígenas afirmam, finalmente, não é tanto a idéia de que os animais são semelhantes aos humanos, mas sim a de que eles - e portanto nós - são diferentes de si mesmos: a diferença é interna ou intensiva, não externa ou extensiva. Se todos têm alma, ninguém é idêntico a si mesmo. Se tudo pode ser humano, então nada é humano inequivocamente. A humanidade de fundo torna problemática a humanidade de forma. (CASTRO, 2004, 238).

O que temos, sob esse ponto de vista, é uma “epistemologia constante [e uma] ontologia variável - o perspectivismo é um multinaturalismo, pois uma perspectiva não é uma representação" (CASTRO, 2004, p. 240).

\footnotetext{
${ }^{3}$ DELEUZE, G. Le pli. Leibniz et le baroque. Paris: Minuit, 1988.
} 
Feitas essas considerações, algumas indagações emergem: "se os não-humanos são pessoas e têm almas, em que se distinguem dos humanos? E por que, sendo gente, não nos vêem como gente? Os animais vêem da mesma forma que nós coisas diversas do que vemos porque seus corpos são diferentes dos nossos." A diferença tem a ver com a morfologia corporal, pois uma figura humana pode ocultar uma afecção serpente. $\mathrm{O}$ corpo, assim, "é um conjunto de maneiras ou modos de ser que constituem um habitus"; é um “(...) feixe de afecções e capacidades, e que é a origem das perspectivas.” Essas considerações, levam o autor a afirmar que “(...) o perspectivismo é um maneirismo corporal." (CASTRO, 2004, p. 240) e nos faz prosseguir em sua comparação entre o etnocentrismo ameríndio e o europeu. Este "consiste em negar que outros corpos tenham a mesma alma"; aquele "em duvidar que outras almas tenham o mesmo corpo." (CASTRO, 2004, p. 241). Ou seja, tudo que existe sobre a face da terra tem alma, ainda que sua forma corporal seja inespecífica.

No diálogo com Deleuze (apud CASTRO, 2004, p. 244), Castro expande a discussão para pensar que "não há pontos de vista sobre as coisas — as coisas é que são pontos de vista", ou seja, o mundo é composto por diferentes espécies; é o espaço abstrato da divergência entre elas enquanto ponto de vista. A questão na análise dos textos literários selecionados não é saber como as serpentes veem o mundo, mas que mundo se exprime através delas, de que mundo elas são o ponto de vista.

Como vou tratar do mito da cobra grande, creio ser conveniente apresentar alguns aspectos simbólicos desse animal na cultura ocidental, com os quais dialogam particularmente Raul Bopp e Cassiano Ricardo. Sumario aqui o verbete do Dicionário de símbolos de Chevalier e Gheerbrant, para quem tanto a serpente quanto o homem distinguem-se de todas as outras espécies animais. Enquanto o homem está no final de um esforço genético, a serpente (ser frio, sem patas, sem pelos, sem plumas) está no início desse esforço. Homem e serpente são opostos complementares; há no primeiro algo de serpente, situado onde seu entendimento tem menor controle. Seria no inconsciente? Psicanaliticamente, a serpente encarna o que há de mais misterioso e incompreensível em nós, a despeito de esse réptil ser considerado um ser comum, simples. É, graficamente, uma linha, um traço; uma abstração encarnada. Não tem começo nem fim. Um sutil movimento torna-a propícia a qualquer metamorfose. Algumas de suas muitas características é ser rápida como um relâmpago, gêmea em si mesma e macho e fêmea a um só tempo. Apresenta um complexo de arquétipos ligados 
à noite fria da origem; vem do mundo de baixo; mora nas profundas camadas da terra ou nas profundas camadas da consciência. Os caldeus utilizavam a mesma palavra para vida e serpente. Sua forma visível é a breve encarnação de uma grande serpente invisível, senhora do princípio vital e de todas as forças da natureza. (CHEVALIER; GHEERBRANT, 1999, p. 814-825).

A lenda da Cobra Grande é um enunciado adaptado em diferentes momentos da história da literatura brasileira: aparece em Martim Cererê, publicado por Cassiano Ricardo em 1928; em Cobra Norato, publicado por Raul Bopp em 1931; em O sumiço da noite, de Daniel Munduruku, publicado em 2006, dentre outros. Nesses diferentes registros, os efeitos de sentido produzidos estão vinculados ao posicionamento ideológico de cada autor e ao contexto histórico no qual escreveram. A propósito do enunciado, Michel Foucault assim o apresenta:

[à] primeira vista, o enunciado aparece como um elemento último, indecomponível, suscetível de ser isolado em si mesmo e capaz de entrar em um jogo de relações com outros elementos semelhantes a ele; como um ponto sem superfície mas que pode ser demarcado em planos de repartição e em formas específicas de grupamentos; como um grão que aparece na superfície de um tecido de que é o elemento constituinte; como um átomo do discurso. (FOUCAULT, 2000, p. 90).

O enunciado como componente que auxilia no recorte temático deste trabalho; o perspectivismo como categoria de análise e o aspecto simbólico da serpente na cultura ocidental me permitem uma triangulação necessária para abordar comparativamente, a partir das condições de produção, os livros que constituem objeto de reflexão deste texto.

\section{O mito da Cobra Grande como discurso literário}

Cassiano Ricardo compartilhou a vida modernista brasileira a partir dos órgãos de imprensa e como um dos líderes dos grupos Verde-Amarelo e Anta. Teve longa carreira literária, viveu quase um século (1895-1974) e Martim Cererê contou com várias reedições desde 1928, ano de seu lançamento. São ao todo 24 edições até o ano de 2009. Influenciado pelo indianismo do grupo Anta, os poemas tratam da invenção de um passado mítico para o Brasil à moda modernista, com o autor recuperando modelos mitológicos cosmogônicos da tradição ocidental de onde emerge o Brasil-menino, além de explicitar a ambição de revelar os eventos que subjazem à formação étnica brasileira. 
A primeira edição foi ilustrada por Di Cavalcanti com motivos indígenas. A essa forma se junta um conteúdo bastante conversador da história oficial do país, com a chegada dos portugueses e os contatos iniciais com os indígenas; a busca dos africanos que seriam aqui escravizados, passando pela colonização do interior com os bandeirantes, a celebração do mito das três raças, noção corrente no senso comum e desenvolvida por Darcy Ribeiro em muitas de suas obras, cujas origens remontam a Carl Friedrich Philipp von Martius. O naturalista alemão propôs a expressão em trabalho escrito para um concurso do Instituto Histórico e Geográfico Brasileiro. A ideia era incorporar à nossa história a concepção de que o país se formou etnicamente da mescla das três raças, alimentando o mito de uma integração racial sem conflitos, a despeito da resistência de indígenas e de escravizados.

Martim Cererê contém 77 poemas, seis partes e uma trama única, qual seja: a noite desapareceu das terras brasileiras. O guerreiro nativo Aimberê e o português Martim desejam se casar com Uiara, “(...) uma mulher / verde olho de ouro / vestida de sol (...)" (RICARDO, 2009, p. 28), filha da Cobra Grande. A Uiara, metáfora das terras brasileiras, porém, apresenta uma condição para aceitar o pedido: "É de haver noite, na terra." (RICARDO, 2009, p. 31). O indígena recebe da Cobra Grande a noite dentro do fruto de tucumã, mas descobre que foi enganado quando encontra Pererê, que assim lhe diz: "“Seu idiota, não percebe / que a Cobra Grande te deu / um oco, dentro do coco?"” (RICARDO, 2009, p. 42).

O herói português promete trazer a noite indo buscá-la no continente africano “"(...) onde jazem os povos a quem nega o filho de Climene a cor do dia" (RICARDO, 2009, p. 64). Tendo trazido a noite, Uiara se casa com o português e com ele dá início à raça dos gigantes de botas, também conhecidos como bandeirantes, os quais com sua marcha para o oeste seguem colonizando o interior do país. O que nos interessa mais de perto aqui é o poema “A Cobra Grande”, no qual a personagem mítica é apresentada. Eis o texto:

\section{A Cobra Grande}

Até que ao fim da estrada no sítio acaba-mundo por onde conduzira as tribos da manhã, o Rei do Mato encontra a Cobra Grande que, 
olhos de safira, se disse sua irmã.

Então a Cobra Grande

lhe fala: "Eu tenho a Noite."

E dá-lhe um espinhento

Fruto de tucumã,

"A Noite mora ao centro desta fruta do mato,

que é espinhenta por fora mas gostosa por dentro..." (E em seu olhar fulgia o abismo da manhã.)

"Vá por este caminho mas não abra o segredo antes da hora marcada, pra seu amor não ser simples palavra vã.

Que se abrires o fruto por encanto ou por medo você terá o castigo de sol e de chão bruto, que te dará Tupã.

Pois o Bicho Felpudo que mora na floresta cum só olho na testa e que usa pés de lã te esconderá os caminhos; cantará a jaçanã. E todas as corujas que são filhas da Noite sairão dos seus ocos e sujarão a cara soltinga da manhã.

E a noite que está dentro deste crespo por fora fruto de tucumã, virará Onça Preta.

E tudo será Noite de não se ver mais nada. E você, Rei do Mato, depois de tanto afã, ficará o vagabundo do sítio acaba-mundo. E vagará, à toa, à frente de seu povo de rechã em rechã, na grande Noite cega, sem amor, sem cunhã." 


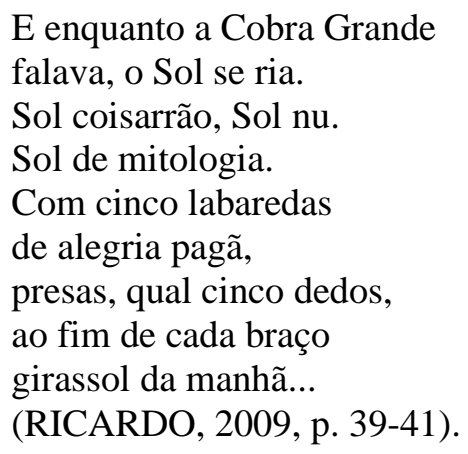

Nesse poema narrativo, com versos oscilando entre 5, 6 e 7 sílabas, alternando versos rimados e brancos, dá-se o encontro entre Aimberê e a Cobra Grande, que tem os olhos de safira, fala por enigmas e é enganadora, como lhe advertiu Pererê. Porém, “(...) mordido pela formiga / verde da curiosidade” (RICARDO, 2009, p. 42), o guerreiro abre o fruto, de onde salta a onça preta. Como consequência de sua impertinência, “(...) a Noite se fez, mas apenas em seu corpo (...)” (RICARDO, 2009, p. 45). Não conseguindo cumprir o desejo de sua amada, o indígena perde a chance de com ela se casar. Entra em cena o português Martim, que traz a noite de terras distantes, alcançando o direito de se casar com Uiara fundando, portanto, a "raça cósmica".

Passemos ao livro de Raul Bopp, que está diretamente vinculado ao movimento antropofágico modernista e propõe uma volta às origens brasileiras, em busca de um modo de viver puro do homem primitivo e de uma natureza intocada pela colonização. Em uma crítica direta ao colonizador português e à cultura europeia por ele representada, Bopp recria poeticamente uma das contradições da primeira dentição modernista: combater a modernidade, em favor do primitivismo, mas sem se rebelar ao progresso civilizacional tão evidente naquele contexto.

Trinta e três poemas compõem Cobra Norato e no seu conjunto pode ser considerado um poema narrativo carregado de aspectos simbólicos e mitos indígenas, com os quais o autor conviveu em sua temporada na Amazônia. A paisagem delineada pelo poema está carregada de traços surrealistas, uma das vanguardas europeias que muito bem se aclimatou na literatura modernista brasileira. Marca a composição desses poemas o verso livre e uma linguagem bastante coloquial, com traços característicos da oralidade e uma prosódia que se deseja nortista. Sérgio Peixoto menciona a possibilidade de

[...] o poema ter influenciado a Antropofagia, e não, como é comum se dizer, ter sido influenciado por ela, [...] já que o texto de Bopp vinha 
sendo rascunhado desde 1921 e corria de mão em mão entre os componentes do grupo. Como se sabe, o Manifesto Antropofágico propunha, além de tudo, a devoração de teorias, da própria História, da Moral, da Política, dos costumes em geral. (PEIXOTO, 2004, p. 157-158).

A estada na Amazônia, conforme diz o próprio Bopp, deixou nele profundas influências, como os cenários imensos constituídos imaginária e surrealisticamente na floresta cifrada. Esse ambiente encantado favorece o resgate antropofágico de mitos indígenas, dentre eles o da cobra grande, que dá origem a Cobra Norato. O enredo conta a história de um herói que busca por sua amada, a filha da rainha Luzia. Para entrar no mato do mal-acabado, ele estrangula Cobra Norato e se zoomorfiza com a pele dela iniciando sua viagem e, como todo herói mítico, vivenciará inúmeras peripécias, como lutar contra a cobra grande e a natureza "malacabada" da Amazônia brasileira. Nesse enfrentamento terá por armas amuletos e feitiçarias e como companheiro de jornada o Tatu-de-bundaseca. Para este momento, apresento o primeiro poema, no qual estão presentes questões relevantes para esta discussão:

I

Um dia

eu hei de morar nas terras do Sem-Fim

Vou andando caminhando caminhando

Me misturo no ventre do mato mordendo raízes.

Depois

faço puçanga de flor de tajá de lagoa

e mando chamar a Cobra Norato.

- Quero contar-te uma história

Vamos passear naquelas ilhas decotadas?

Faz de conta que há luar

A noite chega mansinho.

Estrelas conversam em voz baixa

Brinco então de amarrar uma fita no pescoço

e estrangulo a Cobra

Agora sim

me enfio nessa pele de seda elástica

e saio a correr mundo

Vou visitar a rainha Luzia

Quero me casar com sua filha

- Então você tem que apagar os olhos primeiro

O sono desceu devagar pelas pálpebras pesadas

Um chão de lama rouba a força dos meus passos (BOPP, 2009, p. 3). 
Valendo-se de muitos requisitos estéticos da primeira geração modernista, que fez a "revolução na linguagem", o poema prescinde da pontuação em quase todas as estrofes, os versos são livres, com estrutura paratática, além de se valer da forma dialogada e recorrer a elementos das narrativas populares orais, como as expressões "Um dia", "Depois", "Agora sim", representantes da estrutura tripartite da narrativa. "Um dia" corresponde a uma variação do "Era uma vez" e nos introduz no universo mítico da fantasia, onde a aventura vai se desenrolar. O "Depois" funciona como a expressão "Certo dia", que introduz o problema, ou o desequilíbrio da narrativa, quando o herói elabora um plano para matar Cobra Norato, envenenando-a com uma poção (puçanga) de "flor de tajá de lagoa" e estrangulando-a. O "Agora sim" apresenta ao leitor o problema resolvido, e o herói se enfiando na pele da cobra, recurso que o protegerá em sua jornada pelo interior da floresta indecifrada, em busca da filha da rainha Luzia. Esse primeiro poema cria o ambiente mítico ou lendário no qual o leitor se embrenha para desvendar o Brasil incriado.

Para Maura Voltarelli, Raul Bopp

(...) criou uma variante própria da lenda arranjando uma moça para Cobra Norato - a filha da rainha Luzia por ele buscada durante todo o poema, mas que ele só poderia desposar caso vencesse um ciclo de provas, entre elas, passar por sete mulheres brancas, de ventres despovoados, guardadas por um jacaré, entregar a sombra pro Bicho do Fundo, fazer mirongas na lua nova e beber três gotas de sangue. (VOLTARELLI, 2017, p. 4).

Manejando matéria indígena, Bopp aplica sobre ela a forma da tradição ocidental, em que o herói passa por rituais. Num movimento de redescoberta do Brasil, aquele Brasil que a colonização obrigou a se deslocar para norte e nordeste, o poeta encontra um país ainda envolto em mistério, um Brasil que o Brasil desconhecia. Mesmo desejando incorporar um modo de vida e um pensamento indígena, o que prevalece é a perspectiva de quem vem para descobrir, como afirma o próprio autor:

Ao chegar à Amazônia, senti que estava ante um cenário diferente, de uma violência desconcertante. A linha constante de água e mato era a moldura de um mundo ainda incógnito e confuso. A impressão que me causava o ambiente, na sua estranha brutalidade, escapava das concordâncias. Era uma geografia do malacabado. As florestas não tinham fim (BOPP, 1974, p. 21). 
Voltarelli argumenta que esse encontro com o outro indígena e a floresta amazônica favorece a abertura do poeta para o essencial da experiência antropofágica: o movimento de ir na direção do outro até tornar-se outro. (VOLTARELLI, 2017). Mas convém destacar que a primeira impressão é muito semelhante à do colonizador, qual seja, a de "um mundo ainda incógnito e confuso".

Passemos agora a Daniel Munduruku, autor de $O$ sumiço da noite. Paraense da etnia mundurucu, além de escritor, é professor, com graduação em Filosofia, História e Psicologia; mestrado em Antropologia social e Doutorado em educação pela USP. Atua como diretor-Presidente do Instituto Uk'a - Casa dos Saberes Ancestrais em Lorena SP, onde é membro da Academia de Letras. Já recebeu vários prêmios no Brasil e no exterior: Jabuti, Academia Brasileira de Letras, Érico Vanucci Mendes (CNPq), Tolerância (UNESCO) e por duas vezes a Comenda do mérito cultural, uma honraria do governo brasileiro. $\mathrm{O}$ autor viaja muito pelo Brasil e pelo exterior proferindo palestras sobre a cultura indígena. Em Bate Papo no Itaú Cultural em 2018, Munduruku fez algumas afirmações que nos ajudam a compreender algo sobre o sujeito e seu lugar de enunciação:

Eu sou um dos primeiros escritores indígenas que tem no Brasil, que escreveu para além de seu povo, para a cidade. Para as crianças urbanas. Portanto, quando a gente é pioneiro, a gente se sente sozinho. $\mathrm{Eu}$, como educador, criado dentro da urbanidade, dentro da cidade, eu pensei em fazer algo para as crianças da cidade (...) Nesse sentido, mais do que pertencer a uma geração, eu fui criador de uma geração de jovens escritores indígenas. Hoje nós somos mais de trinta autores e muitos deles nasceram a partir desse trabalho de formação mesmo, porque a escrita para nós é muito nova. Se pensar que nós temos escolas indígenas só há trinta anos (...) De vinte anos para cá é que começaram a surgir escritores pensando na sociedade brasileira como um todo. (...) Eu costumo dizer que eu nasci índio por uma benção do universo, mas quando eu quis atuar na sociedade, eu escolhi ser professor, por entender que o professor é aquele que professa uma crença no ser humano. Eu, na minha atuação humana, na minha atuação profissional, eu tenho procurado alertar as pessoas para isso: de que eu acredito, eu acredito na possibilidade de a gente ser humano de fato, de verdade; não apenas no discurso, mas na atitude. E é isso que eu busco. ${ }^{4}$

As escolhas do autor o situam como aquele que escreve "para fora", "pensando na sociedade brasileira como um todo", atuando, de certa forma, como tradutor da

\footnotetext{
${ }^{4}$ Bate Papo Itaú Cultural. Disponível em: https://www.youtube.com/watch?v=8D4RF2CqR68. Acesso em: 11/07/2019.
} 
cultura indígena, ocidentalizando-se sem deixar de ser indígena. Sua escolha por escrever para o Brasil exigiu acesso ao capital cultural ocidental-brasileiro-colonizado, mas com conteúdo propriamente indígena, o que lhe dá a oportunidade de suplementar, com sua literatura, os discursos oficiais que produziram narrativas muitas vezes estigmatizantes sobre os indígenas.

$O$ sumiço da noite é uma narrativa infantil, que recupera um mito indígena, narrado como lenda, pois o fato histórico é transformado sob o efeito da imaginação poética. Para os indígenas, contudo, a efabulação de um evento não lhe subtrai a carga de verdade e é como tal que "as lendas se transformam em tradição e os povos vão passando seus conhecimentos de geração em geração.” (MUNDURUKU, 2006, p. 30). O relato conta como estavam apreensivos os habitantes da floresta: indígenas, fauna e flora, devido ao desaparecimento da noite, que foi escondida numa cabaça por uma Surucucu. No confronto com a serpente, Karu Karu, o bravo guerreiro, vai até ela três vezes levando um presente com o qual possa negociar o retorno da noite para todos. No primeiro encontro, ele oferece o arco e a flecha, que a cobra recusa por não ter braços para manejá-los. Mas reconhecendo o esforço do herói de negociar a situação, dá-lhe uma pequena porção da noite para que a floresta possa descansar um pouco. Antes, contudo, pede outro presente. No segundo encontro, é oferecido à serpente um belo maracá, o qual ela recusa, por não ter mãos para sacudir, mas Karu Karu sugere amarrálo em sua cauda. Sugestão aceita, o indígena recebe uma porção maior da noite, depois de a serpente pedir-lhe porções de veneno para distribuir entre todas da sua espécie, já que seria a única arma para se defenderem dos inimigos. Muito veneno é fabricado e oferecido à serpente no terceiro encontro em troca da noite para os habitantes da floresta.

\section{Algumas interpretações possíveis}

Passemos agora à última parte deste texto, quando faço uma análise comparativa da apropriação do mito da Cobra Grande, com base principalmente nas discussões de Eduardo Viveiros de Castro sobre o Perspectivismo, em diálogo com a concepção de enunciado e as contribuições do Dicionário de símbolos.

A Cobra Grande em Cassiano Ricardo e em Raul Bopp pode ser compreendida como a porção inconsciente, primitiva da nossa história, justificando ser vencida pelo 
homem humano. Os ardis de linguagem de cada autor, mesmo diferentes, levam ao um resultado semelhante. Em Martim Cererê, a cobra é a falaciosa; engana o indígena e favorece o português, enquanto em Cobra Norato, o réptil é enganado; sua pele serve de roupa/disfarce para a jornada do herói floresta adentro. Nos dois livros, o indígena ocupa posição inferior na escala hierárquica. Teria ele alma? Talvez fosse essa a pergunta do homem branco a respeito de sua humanidade, já que sobre os animais não restam dúvidas de sua não-humanidade. São seres falantes; interagem com o humano, mas correspondem ao universo das fábulas, relato alegórico ou não, convém lembrar, no qual humanos e animais interagem por linguagens comuns, estando os animais quase sempre a serviço do êxito humano. Em Martim Cererê a natureza, representada pela Cobra, favorece o forasteiro, o que vai colonizar, obedecendo a uma verossimilhança histórica, ao passo que em Cobra Norato o humano logra a cobra roubando-lhe a pele, assumindo as feições desta em sua travessia pela floresta.

O homem, vestido de animal, transforma-se nesse animal, revelando para si mesmo a distintividade "natural" do seu corpo (CASTRO, 2004, p. 46). Viveiros de Castro lembra-se de não haver "na etnologia e na mitologia amazônicas, animais assumindo o corpo humano como uma espécie de roupa. A forma humana é um corpo (alma) dentro do corpo físico. Ao vestir-se com as roupas (pele) de Cobra Norato, o herói assume para si um terceiro corpo, ao qual podemos chamar de disfarce, que lhe dá o conforto necessário para transitar pela floresta entre fauna, flora e indígenas. Nesse caso, a roupa lhe dá condições de ativar os poderes de um corpo no outro. Ou seja, o disfarce de Cobra Norato o transforma em cobra para os indígenas, que assim o veem. A questão é que, sob essa perspectiva, o ardil do homem branco é apenas uma estratégia, uma dissimulação, já que os seres a serem dominados - natureza e indígenas desconhecem o ponto de vista em vigor, o que se esconde sob a aparência, já que tudo é gente, é humano.

Em ambos os autores, para que o Brasil menino ganhe existência, é preciso superar nossa história primitiva, pré-colonial, para dar lugar ao primitivismo colonial, que emerge do encontro entre o europeu, o ameríndio e o africano garantindo, portanto, que tanto a história quanto a literatura estejam a serviço de um humanismo colonial. $O$ sumiço da noite, por sua vez, parece performar um humanismo distinto daquele dos modernistas, já que em sua narrativa a Cobra não é um ser inferior, não será eliminada para que os humanos existam; ela também é humana. Há entre os indígenas, que estão 
sem a noite, e a Surucucu, uma "diferença ontológica de grau, mas não de natureza", já que o réptil que subtraiu a noite é dotado de alma; é um ser que age (eliminou a noite da floresta), com uma intenção (barganhar com os humanos homens sua sobrevivência) e é reflexivo (tem capacidade de pensar a si mesmo). Há, portanto, o reconhecimento de que o mundo não existe só para os humanos "dotados de consciência e de cultura", já que a Surucucu se vê a si mesma como humana.

$\mathrm{Na}$ narrativa de Munduruku, a diferença de ponto de vista entre o indígena e a Cobra é anulada e exacerbada, pois cada um se vê a si mesmo como humano, mas age manifestando sua natureza distintiva e definitiva de animal (humano para o indígena e ex-humano para a cobra). O indígena é o humano que continuou igual a si mesmo, enquanto a Surucucu perdeu os atributos humanos. Contudo, tendo sido humana uma vez, a Cobra continua a sê-lo, "mesmo que de modo não-evidente" (CASTRO, 2004, p. 230). Portanto, não há uma oposição, na narrativa de Munduruku, entre humano (indígena) e não-humano (cobra), já que "natureza e cultura são parte de um mesmo campo sociocósmico." (CASTRO, 2004, p. 234).

Assim sendo, o mundo que se exprime através da Cobra nos relatos modernistas não cria um ponto de vista próprio, pois é desconsiderado, já que a cobra, como ser mítico dotado de algum poder, agiu um favor do colonizador em Martim Cererê; foi estangulada, no caso de Cobra Norato, enquanto em $O$ sumiço da noite existe entre humanos (indígenas) e ex-humanos (cobra) uma negociação que permite inferir haver uma percepção mútua de como o mundo se exprime através dos indígenas e de como o mundo se exprime através das cobras.

Concluindo, podemos dizer, com Foucault, que não é o enunciado em si, ou seja, o que foi dito, o que deve ser enfatizado, mas o como, o onde, o por que e por quem foi dito; são esses elementos que atualizam e descristalizam os enunciados que nos permitem ver a história sob outros ângulos. Os dois escritores modernistas, vinculados a um projeto de redescoberta crítica do Brasil, o fazem ainda na lógica de uma episteme colonial que submete o indígena e a terra que ele habita. É o humanismo para os humanos. Já em $O$ sumiço da noite, o livro é o suporte e a literatura, mais amplamente, é o gênero da escrita, assim como o foi para toda uma tradição de escritores brasileiros que se alimentaram da cultura indígena para produzir literatura; além disso, o português é a língua comum a esses escritos. Entretanto, o lugar da enunciação e o sujeito da escrita assinalam algumas mudanças nos paradigmas desse discurso. Daniel Munduruku 
reescreve a lenda, uma entre milhares, a qual, "como um grão que aparece na superfície de um tecido de que é o elemento constituinte", nos obriga a repensar quais a razões de, 500 anos depois, ainda insistirmos em percepções estigmatizantes sobre o indígena brasileiro.

Na contramão desse projeto, o indígena, a terra e os animais são tratados em $O$ sumiço da noite pela lógica perspectivista, a partir da qual a humanidade é um atributo comum. Ainda que imerso na cultura ocidental e se valendo dela para escrever e publicar seus livros, o que percebo no trabalho de Munduruku é que as culturas indígenas e seus povos deixam de ser objeto da observação quase que onisciente do outro, para ser problematizada a partir de teorias próprias, alterando a forma de se compreender esse conhecimento. Então, ao escolher ser professor e escritor, Munduruku se coloca como um agente que pensa e discute a cultura ameríndia como ameríndio que é. Este me parecer ser o salto para o novo humanismo, pois permite que o Outro possa ser objeto de seu próprio conhecimento e saber.

\section{Referências}

BATE PAPO ITAÚ CULTURAL. Disponível em: https://www.youtube.com/watch?v=8D4RF2CqR68. Acesso em: 11 julho 2019. 15 h47.

BOPP, Raul. Cobra Norato. Rio de Janeiro: Civilização Brasileira, 1978.

CASTRO, Eduardo Viveiros de. Perspectivismo e multinaturalismo na América indígena. $O$ que nos faz pensar, $\mathrm{n}^{\mathrm{o}}$ 18, p. 225-254, set. 2004. Disponível em: http://www.oquenosfazpensar.fil.puc-

rio.br/import/pdf_articles/OQNFP_18_13_eduardo_viveiros_de_castro.pdf. Acesso em: 10 maio 2021. 20h00.

CHEVALIER, Jean; GHEERBRANT, Alain. Dicionário de símbolos: mitos, sonhos, costumes, gestos, formas, figuras, cores, números. 14. ed. Rio de Janeiro: José Olympio, 1999. p. 814-825. (Verbete: Serpente).

FOUCAULT, Michel. A arqueologia do saber. Trad. Luiz F. Baeta Neves. 6. ed. Rio de Janeiro: Forense Universitária, 2000.

MUNDURUKU, Daniel. O sumiço da noite. Ilustrações Inez Martins. São Paulo: Editora Caramelo, 2006. Coleção Crônicas Indígenas.

PEIXOTO, Sérgio. Cobra Norato: uma introdução à leitura. Revista do CESP, v. 24, nº 33, p. 154-181, jan.-dez. 2004. Disponível em: http://www.periodicos.letras.ufmg.br/index.php/cesp/article/view/6682. Acesso em: 15 de maio 2021. 15h47. 
RICARDO, Cassiano. Martim Cererê. 15. ed. Rio de Janeiro: José Olympio, 1981.

VOLTARELLI, Mara. Perspectivismo e antropofagia em Cobra Norato, de Raul Bopp. Palimpsesto, $\mathrm{n}^{\mathrm{o}}$ 24, jan.-jun., p. 162-176, 2017. Disponível em: https://www.epublicacoes.uerj.br/index.php/palimpsesto/article/view/34829/24609. Acesso em: 13 jul. 2019. $18 \mathrm{~h} 00$. 